\title{
AGRICULTURAL MACHINES MANAGEMENT AND ASSIGNMENT SYSTEM OF HEILONGJIANG RECLAMATION AREA
}

\author{
Xi Wang ${ }^{1}$, Chun Wang ${ }^{1, *}$, WeiDong Zhuang ${ }^{1}$, Hui Yang ${ }^{1}$ \\ ${ }^{1}$ College of Engineering, Heilongjiang August 1st Reclamation Land University, Daqing, \\ China, 163319; \\ * Corresponding author, Address: Heilongjiang August 1st Reclamation Land University, \\ Daqing, 163319, HeilongjiangProvince,P.R.China,Tel:+86-459-6819006,Fax:+86-459- \\ 6819006,Email:wangchun1963@162.com
}

\begin{abstract}
To meet the need of modernization of agricultural machines management in Heilongjiang Reclamation Area, further boost the level of large-scale modernized agricultural production, and improve agricultural machines management, agricultural machines management and assignment network system has been established. The system has realized agricultural machines management by network and management departments of all levels can obtain the information of agricultural machine assignments on the internet. In this way, agricultural machine management has been improved.
\end{abstract}

Keywords: agriculture machines, agriculture information, network system.

\section{PREFACE}

At present, Heilongjiang Reclamation Area has become the largest national farm group where mechanization degree is the highest. Heilongjiang Reclamation Area takes modern agricultural machine equipment as direction and develops modern agriculture decisively. To meet the need of modernization of agricultural machines management in Heilongjiang Reclamation Area, further boost the level of large-scale modernized agricultural production, and improve agricultural machines management,

Please use the following format when citing this chapter:

Wang, X., Wang, C., Zhuang, W. and Yang, H., 2009, in IFIP International Federation for Information Processing, Volume 293, Computer and Computing Technologies in Agriculture II, Volume 1, eds. D. Li, Z. Chunjiang, (Boston: Springer), pp. 635-641. 
agricultural machines management and assignment network system has been established. The system has realized agricultural machines management by network and management departments of all levels can obtain the information of agricultural machine assignments on the internet. In this way, agricultural machine management has been improved.

\section{MANAGEMENT AND ASSIGNMENT SYSTEM OF AGRICULTURAL MACHINE}

Management and command system of agricultural machines (Fig.1) is composed of command and management center, management network system, land block remote sensor material, farm geographical information system, GPS dynamic tracing system, remote video monitoring system, remote wireless video monitoring system for working machine, statistic and calculating of single unit workload, statistic of historical data for agricultural machine, experience communication system for machine usage, wireless data acquisition system for producing base environment etc.

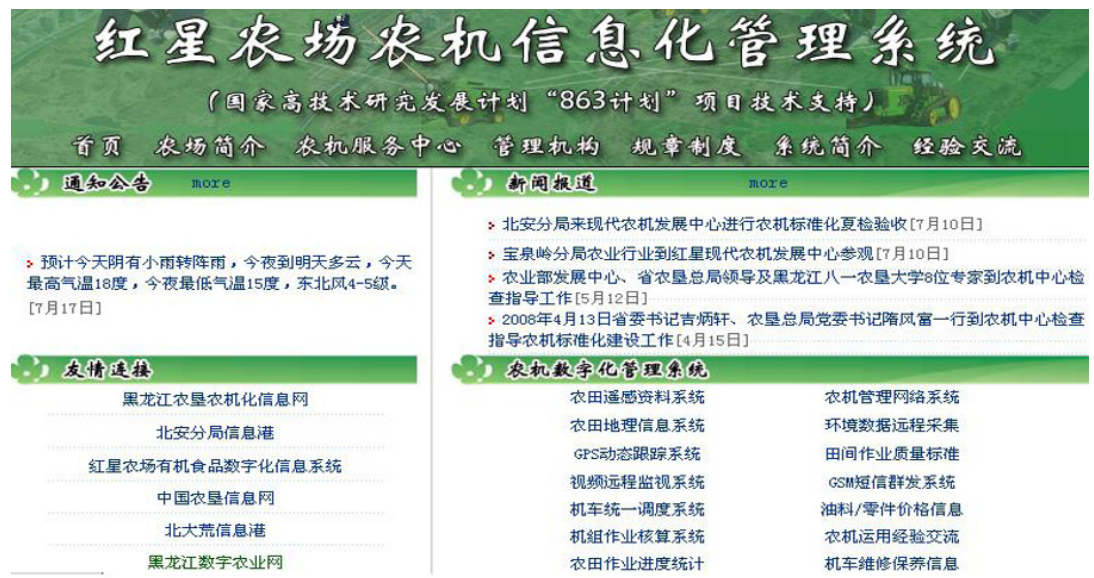

Fig. 1 Management and Command System of Agricultural Machines

\subsection{Command and Management Center for Agricultural Machine}

Command and management center for agricultural machine is centered with information management system. The center is cored by $3 \mathrm{~S}$ (GPS、 GIS、RS ) technology and network technology. 126 inches plasma screen wall is used as display platform for machine management information and 
video monitoring information. The plasma screen wall constitutes $3 * 342$ inches plasma monitor screen. The size of the screen wall is $2880 \times 1670 \times 176$ $\mathrm{mm}$, and the system is equipped with 1 RGB matrix, 1 video and audio matrix, control computer for plasma screen, and 1 operation display computer.

\subsection{Management Network System for Agricultural Machine}

In order to meet the need of management modernization of agricultural machines, Heilongjiang Reclamation Area has boosted large-scale intensive modern agricultural productivity and agricultural machine management. At the same time, the Area has established network information system for agricultural machine management with internet technology. The current basic condition of management which includes management staffs, conditions of drivers, power machines management, conditions of agricultural equipment and management, historical data of machines etc can be recorded in management database for agricultural machines. The network management can not only allow management staffs to inquire on the internet but also bring convenience to superior management department for mastering the agricultural machine management information promptly.

\subsection{Remote Sensing Material of Land Blocks}

The satellite remote sensing images with graphics resolution of 2.5 meters can cover the whole farm land.After calculating on fixed point and geometry adjust, the ground position and space information which includes land blocks, roads, waters, forests, reservoirs, residences etc can be acquired. This facilitates general division of farm land and producing management. The remote sensing image data is transmitted to system server and the function including zooming out, zooming in, moving, distance calculating and land area calculating can be practiced through Web GIS software GeoBeans.

\subsection{Farm Geographic Information System}

By recognizing remote images and adjusting on the port, acquiring crop farming information relating to the space, the crop database can be established. The system can realize the function such as zooming in, zooming out, moving, land block inquiring, latitude and longitude of current position, distance calculating, land area calculating etc by using Web GIS 
software GeoBeans introduced from Remote Sensing Institute of Chinese Academy of Science. The basic condition and geographical position of certain number can be acquired on computer which has stored land map and land number information.

\subsection{GPS Dynamic Tracing System}

The working engines are equipped with GPS tracing equipment which can receive the current geographical information (latitude, longitude, height), time and moving status (speed, direction) by GPS receiver. The information can be transmitted to agricultural machine management database through GPRS. The working engine conditions including land block, direction, speed and working trace can be required on the internet and displayed on the screen of the center.

\subsection{Remote Video Monitoring System}

There is an infrared camera which can be rotated and its focus can be adjusted on the farm garage center. The network video server connects the internet and management staffs of all levels can monitor the farm garage condition so that garage management and fire and stealing can be prevented. The network video server is used to transmit digital video and audio signals through internet.The server adopts programmable high-speed digital signal processor (DSP) which can make the image transmitted with no delay and more clear. The management, configuration, and monitor and other operation else can be accomplished through Internet Explore.

\subsection{Remote Wireless Video Monitoring System for Working Engines}

The images of tractors or harvesters equipped with wireless video monitoring system can be transmitted to the management and command center through digital transmission equipment while they are working on the farm. Management staffs can monitor the current working condition of agricultural machines on the screen such as whether the machine is working or not and the equality of working etc.

The remote wireless video monitor on Red Star Farmland adopts COFDM technology. Image video and audio can be transmitted with no delay and the transmission distance can reach $20 \mathrm{Km}$. The remote wireless video monitor on Seven Star Farmland adopts wireless local area network (802.11b、802.11a) technology. The system can transmit D1 format highdefinition images to all directions or one certain direction. The working 
machine which adopts $802.11 \mathrm{~b}$ protocol transmits the images to the base station of management area which adopts 802.11 a protocol. The images received from base station can be displayed on the screen.

\subsection{GSM Short Message Group-Sending System}

GSM is kind of global mobile communication system. Management and Command Center can send short messages to staff's mobile phone in a short time by using the GSM short message platform. The communication between the center and staffs in this way can lower much more communication costs and boost working efficiency. The staffs can receive the information reminded such as agricultural machine trends, new technology and maintain of machines on time by their own phones. This can facilitate organizing management, mobilizing of machines and promoting of new technology.

\subsection{Assignment Schedule Statistics and Calculating System}

Every administrative region can relay assignment schedule of each day of each period through computer network. The staffs in charge of management can get the assignment schedule information promptly and the system itself can also send machine-maintain requirement according to quantity of each machine.

\subsection{Assignment Plan System}

At the beginning of each year, the Management and Assignment Center puts forward the general design of machine's assignment according to the planting arrangement of the farm and organizes working machines to implement. The general plan of machines assignment including spring soil tillage, seeding, middle-planting management, harvest, autumn soil tillage etc can facilitate scientific management and organization of productivity.

\subsection{Assignment Statistics and Calculating of Each Unit}

The program designed for each unit assignment can calculate the quantity of assignment, accumulated incomes, accumulated oil consumption, accumulated output, standard oil consumption and costs of per unit. The information is input by administrative region and relayed to the Center. 
Through exact assignment calculating of each engine unit, precise management can be attained.

\subsection{Historical Material Statistic}

The whole agricultural machines data such as the numbers of wheel tractors, pedrail tractors, matched agricultural machine equipments, harvesters, and total driving force etc can be required on the computer by program designed and displayed in the form of histogram or line chart on the screen.

\subsection{Communication System for Experience}

The experience communication website has been designed and staffs can exchange daily maintenance experience and technology improvement. If the new information and technology is input on the network, the drivers can acquire these on the internet at home.

\subsection{Wireless Data Acquisition System}

The production base of the farm is equipped with wireless environment data acquisition system which can acquire the environment data such as temperature, soil temperature, environment moisture, sunshine etc and then transmit the data to network database through GPRS. The staffs can browse the environment parameters on the internet and the system can provide support for production decision.

\section{USAGE EFFECT OF THE SYSTEM}

The Seven Star farm Research and Development Center and Red Star farm Modern Agricultural Machine Development Center on Heilongjiang Reclamation Area take the idea of "base upon precision agriculture and develop modern agricultural machines" as construction direction and intend to acquire the effects including saving of resource consumption in the largest degree and gaining the highest profit by high-technology devotion such as 3S technology (GPS, GIS, RS). The network information system is used to assign the work for all the machines. The management of agricultural machines is converted from dispersive, extensive management to intensive network management. The planters, machine owners, management staffs can inquire about production condition and assignment conditions, incomes and maintenance of machines on the internet. The new trend of agricultural 
machines and technology improvement information can be sent to drivers by short messages. When the machines need to be examined and repaired, the workers can take the advantage of the computer in training room to inquire about technology information and exchange machine maintenance experience which can satisfy the technology need of staffs and boost the whole technology.

\section{CONCLUSION}

The construction of agricultural machine management and assignment system of Seven Star and Red Star farm in Heilongjiang Reclamation Area can adequately exert the advantage of large-scale modern agricultural machine assignment and boost the agriculture mechanism level. The system has brought network, digital and information to agricultural production on farmland. The scientific, standard, quantitative and high effective management can effectively promote the optimization of agricultural economic structure and pioneer new mode for exploring agricultural machine management under the new system and condition of China.

\section{REFERENCES}

Fan Luxiong. The Agricultural Expert System and Development Tools [M].Beijing :Qinghua University Press, 1999

Li Qiang, Wang Xi, Zhuang weiDong. Research of Agricultural Machine Information Management System Based on Network [J].Agricultural Network Information, 2007.15(11):13 14 (in Chinese)

Yang Baozhu, Li Ai-ping, Research and Application of the Network and Computer Agricultural Expert System Development Platform (PAID) [J] High-tech Communication .2002,12,(3):5-9

Zhao Zeying .Study on Recommended Fertilization Model and its Parameter System in Intelligent Management System for Corn Production of Guizhou [j] .Guizhou Agricultural Sciences,2004,32(3):24-27

Zhuang weiDong, Wang Chun, Wang Xi. Design and Development of Precision Agriculture Website of Heilongjiang Reclamation Area[J]. Journal of Agricultural Mechanization Research,2005.14(4):251 252 (in Chinese) 